\title{
ACCURACY OF HALOTHANE VAPORIZERS IN CLINICAL USE
}

\author{
WIILIAM H. NOBLE, B.A., M.D., F.R.C.P.(c)
}

MACKAY IN 1957 stressed the importance of having vaporizers capable of producing accurate and reliable concentrations of halothane. ${ }^{1}$ There have been since many articles evaluating the accuracy of different halothane vaporizers in various experimental situations. ${ }^{2,3}$ These have dealt with vaporizers which were new or had been recently calibrated. Adner and Hallen ${ }^{4}$ were the first to check the calibration of Fluotec vaporizers after they had been in clinical use for a period of time. The effect of ventilators on vaporizer accuracy has been well studied by Gordh, ${ }^{5}$ Hill and Lowe, ${ }^{6}$ Cole, ${ }^{7}$ and Andreesen and Bay, ${ }^{8}$ and many articles have described discrepancies at low gas flows between vaporizer settings and delivered concentrations.

Because of doubt raised during clinical anaesthesia concerning the accuracy of vaporizers, it was decided to study several types of halothane vaporizers in clinical use to determine their reliability. A new Venturi Circulator ${ }^{9}$ was also included to determine its effect on vaporizer accuracy.

\section{METHOD}

The vaporizers investigated were:

1. Ten Fluotec Mark II vaporizers; one was relatively new but all others had been in constant use for five years. They had never been recalibrated but had been irregularly cleaned, and parts had been replaced by the department of oxygen therapy in the hospital.

2. Two Drager-Vapor halothane vaporizers; both had been in constant use for more than two years with no servicing of any kind.

3. Two Foregger Copper Kettles ${ }^{10}$ in use for less than one and a half years without specific attention.

4. Two new Mark in Fluotec vaporizers.

A Rayleigh Interference Refractometer ${ }^{11}$ measured the concentration of halothane delivered by the vaporizers. The refractometer is described by Hill as "the most accurate method of measuring vapour concentrations for binary mixtures." The principle used by the refractometer is a comparison of the refractive indices of one gas with another. Controlled flows of oxygen were compared with the delivered mixture of oxygen and halothane which had passed over baffles to ensure mixing and was being sampled at a constant $500 \mathrm{cc} / \mathrm{min}$ flow.

As in Figure 1, the Fluotec Mark II and Mark ul vaporizers were removed from the anaesthetic machines and had their delivered concentrations measured at known room temperature and barometric pressure with the fluid level indicating full and empty at a constant $5 \mathrm{~L} / \mathrm{min}$ inflow.

The Copper Kettle and Drager vaporizers were not separated from their gas 


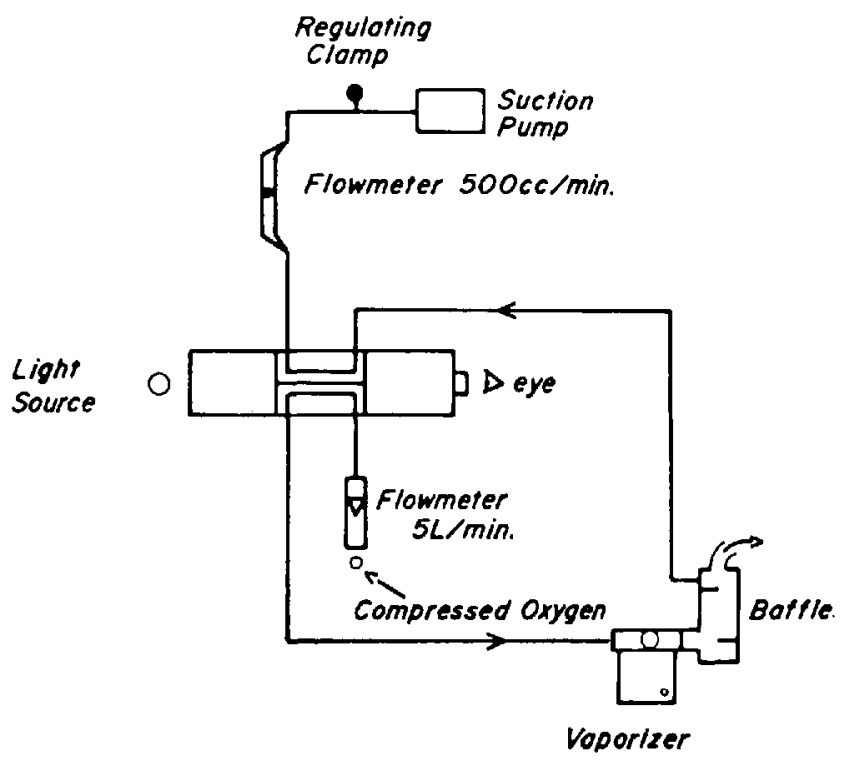

\section{RAYLEIGH INTERFERENCE REFRACTOMETER}

Figure 1. Diagrammatic representation of circuit used to measure the concentration of halothane delivered by isolated vaporizers.

machines but a single NCG rubber tube carried gases to the baffle and this was also tested with the fluid level full and empty at variable flows.

The experimental design included anaesthetic machines in use in the operating theatre tested to withstand 30 p.s.i. without leaking. Figure 2 is a diagrammatic

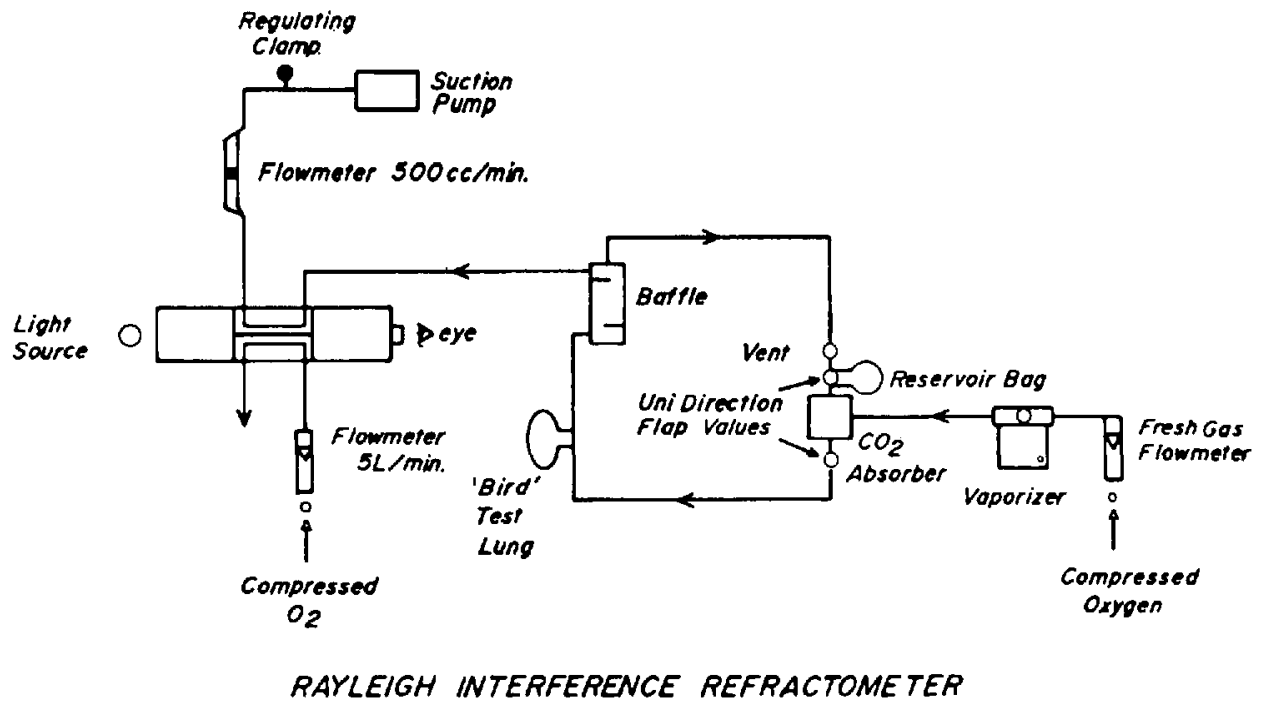

Figure 2. The method used, with anaesthetic machine and circle represented. 


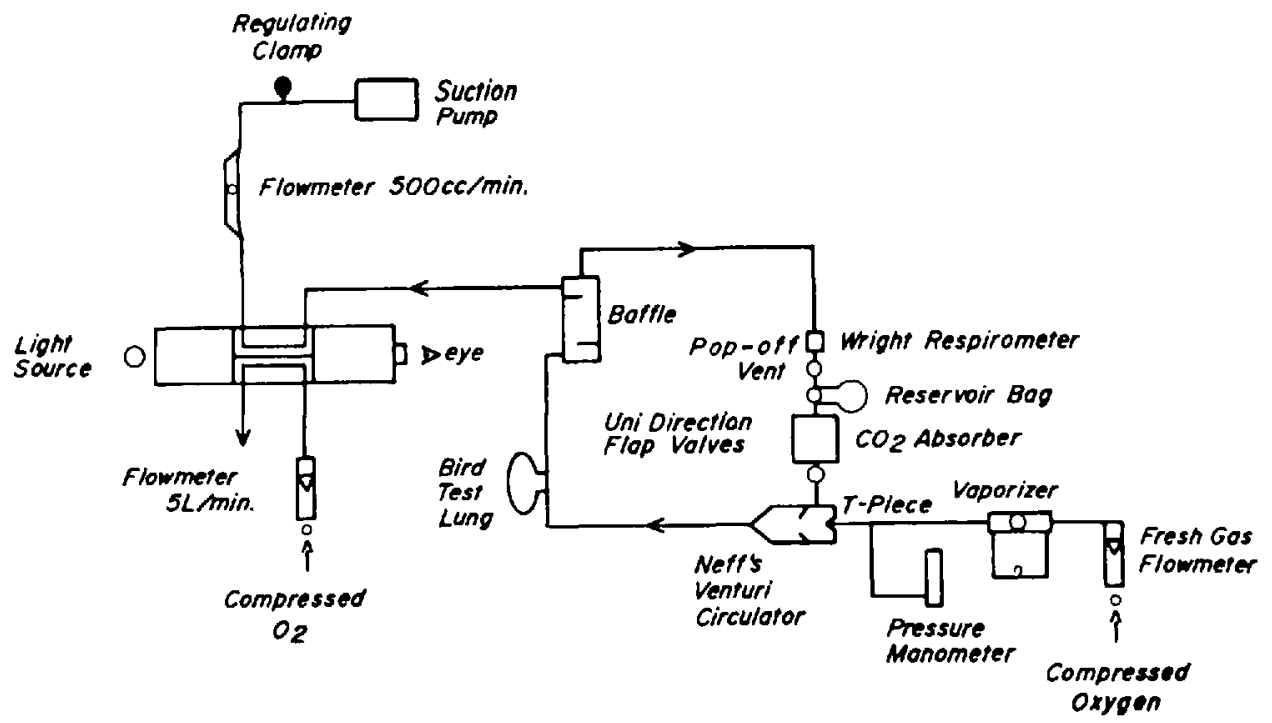

RAYLEIGH INTERFERENCE . REFRACTOMETER

Figure 3. Venturi circulator added into circle system.

representation of the machine with oxygen source, flowmeter, vaporizer, and circle $\mathrm{CO}_{2}$ absorber. After passing through the baffle, the gas sample moves to the refractometer as in Figure 1. The vaporizers were also tested attached to their machines using this semi-closed circle system. Intermittent manual compression of the reservoir bag with pressures less than $5 \mathrm{~mm} \mathrm{Hg}$ was carried out to open directional flap valves and assure mixing.

In Figure 3 Neff's Venturi Circulator is placed within the circle system. The circulator takes an input flow of gas and by the Venturi principle multiplies that flow many times within the circle. A manometer was placed proximal to the circulator to determine the back pressure being exerted into the vaporizer at an oxygen flow of $5 \mathrm{~L} / \mathrm{min}$.

In order to determine the effect of recommended vs local technician servicing, two Fluotec Mark II vaporizers were cleaned by scrubbing the spindle with BonAmi and soaking the pot several hours with ether to remove thymol deposits. The concentrations delivered were again measured in our laboratory and in the laboratory of the manufacturer, who then cleaned and recalibrated both Fluotecs. Again, both Fluotecs were tested in the manufacturer's laboratory and in ours.

\section{Results AND Discussion}

In Figure 4 one can see the marked difference between the indicated and measured vapour concentrations. With the Fluotec Mark II it is noted that deviations tend to be on the low side. At 0 setting no halothane was delivered. Figure 5 indicates the greater accuracy of the Drager-Vapor vaporizer. Again, concentrations tend to be lower than expected but at 0 setting with the control turned to 


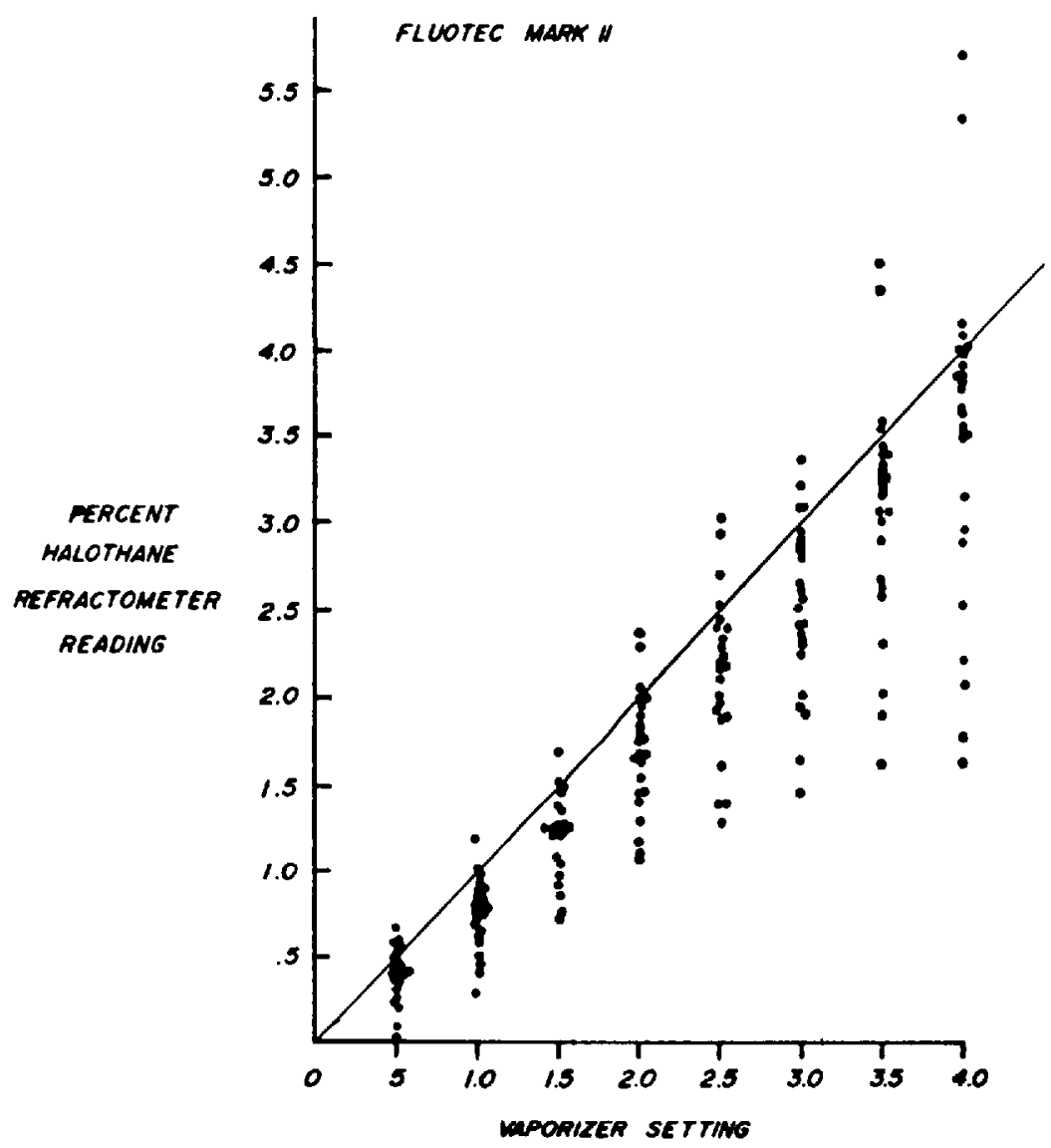

Figure 4. Isolated Fluotec Mark II results.

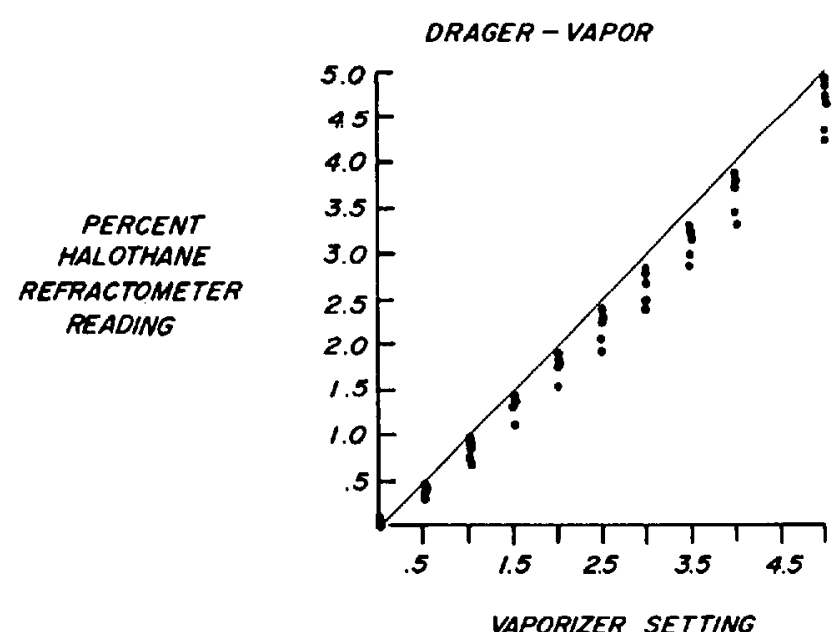

Ficune 5. Drager-Vapor vaporizer results. 
"out of use" a very small amount of halothane was measured. Figure 6 indicates the accuracy of the Copper Kettle vaporizer. Again, at 0 setting with vaporizer turned off, a small amount of halothane was measured in one of the two vaporizers. Figure 7 shows the accuracy of the Fluotec Mark Irr. At 0 setting no halothane was measured.

All the vaporizers have a mechanism for completely shutting off the vaporizer pot from bypass gas. Both Drager vaporizers and one Copper Kettle vaporizer delivered up to 0.1 per cent halothane when apparently shut off. The Fluotec Mark II and Mark III did not deliver halothane when shut off.

Figure 8 is a composite showing per cent deviation against vaporizer setting and indicating that the Copper Kettle and Drager-Vapor vaporizers are more accurate than the Mark II Fluotec after clinical use and no recalibration.

The lower graph in Figure 9 again plots setting against resultant halothane concentration with manual ventilation in the circle system. Concentrations were slightly reduced but followed the same pattern as with the isolated vaporizer in each of the vaporizers studied. Titel et al. ${ }^{\mathbf{2}}$ found that soda lime, when dry, absorbs much more halothane than when wet. Eger, Larson, and Severinghaus ${ }^{13}$ described the solubility of halothane in rubber. This slight lowering of concentration can be accounted for on the basis of rubber and soda lime absorption.

The upper graph in Figure 9 shows that with the Venturi Circulator in use all values were markedly depressed at each setting. With a $5 \mathrm{~L} / \mathrm{min}$ input of oxygen the flows in the circle as obtained on the Wright Respirometer varied between 25 and $32 \mathrm{~L} / \mathrm{min}$ with a back pressure of between 240 and $310 \mathrm{~mm} \mathrm{Hg}$ exerted outside the circle and into the vaporizer. This same back pressure was then created without the Venturi circulator by clamping a single delivery tube from the gas machine as in Figure 10. In the upper graph the upper dots represent concentration delivered without back pressure being exerted. The lower dots represent concentration delivered in the face of $250 \mathrm{~mm} \mathrm{Hg}$ back pressure. The lower graph shows that with the Fluotec Mark w similar back pressure again

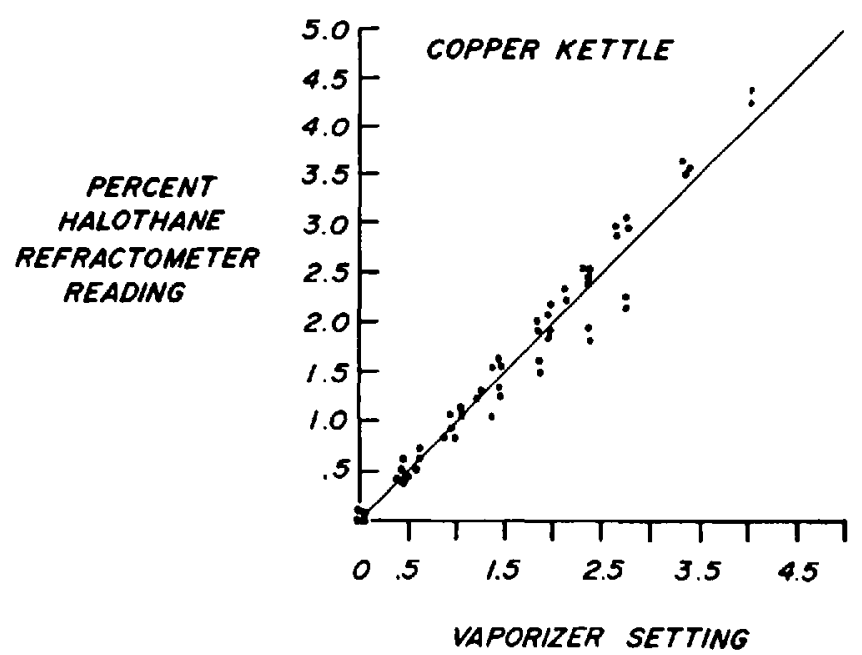

Figure 6. Copper Kettle vaporizer results. 


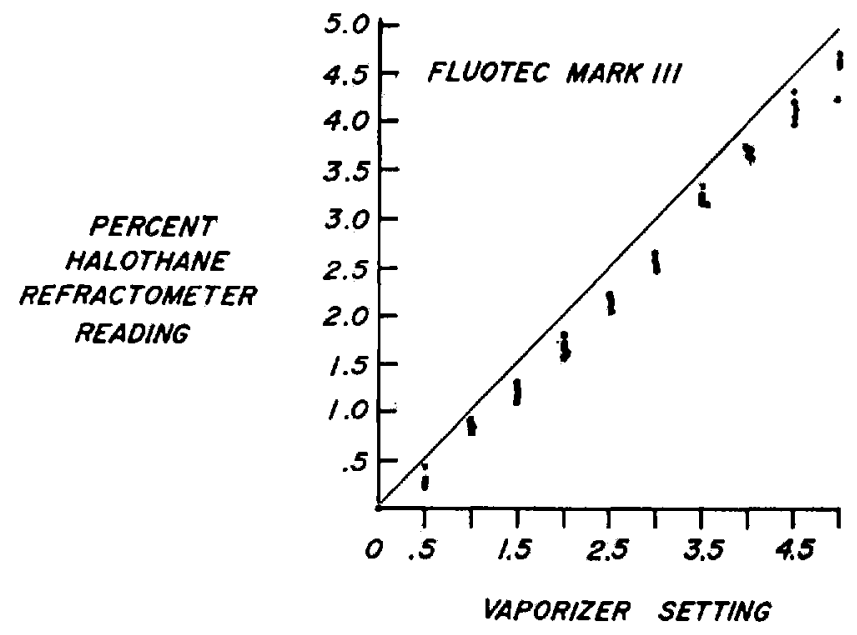

Figure 7. New Mark In Fluotec vaporizer results.

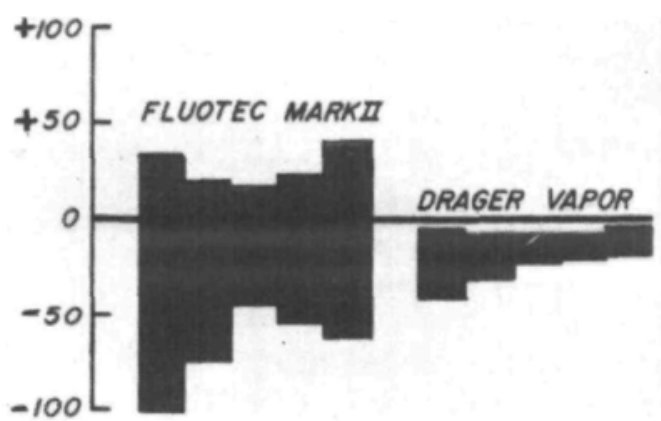

PERCENT

DEVIATION

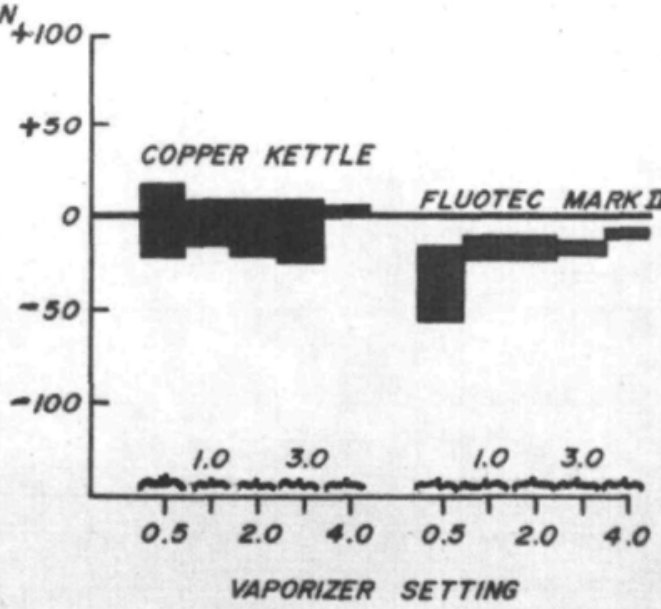

Frgure 8. Comparability of vaporizers in clinical use. 

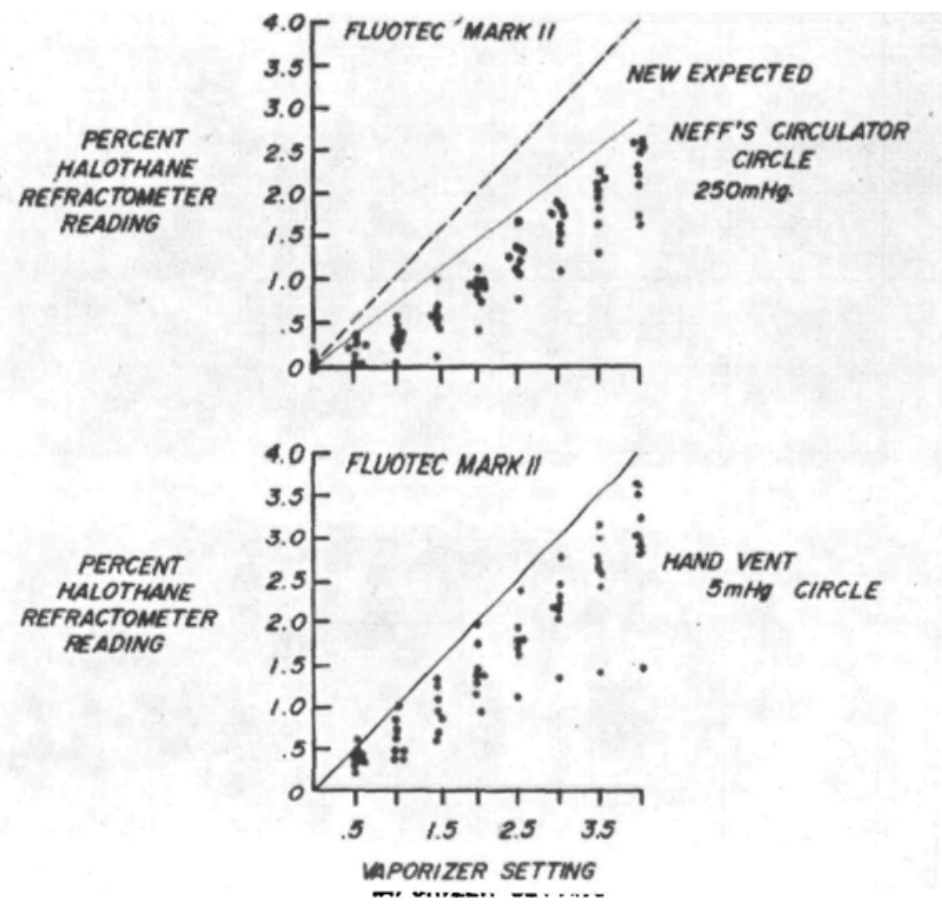

Figure 9. Lower graph shows results using method in Figure 2, Upper graph shows results using method in Figure 3 .

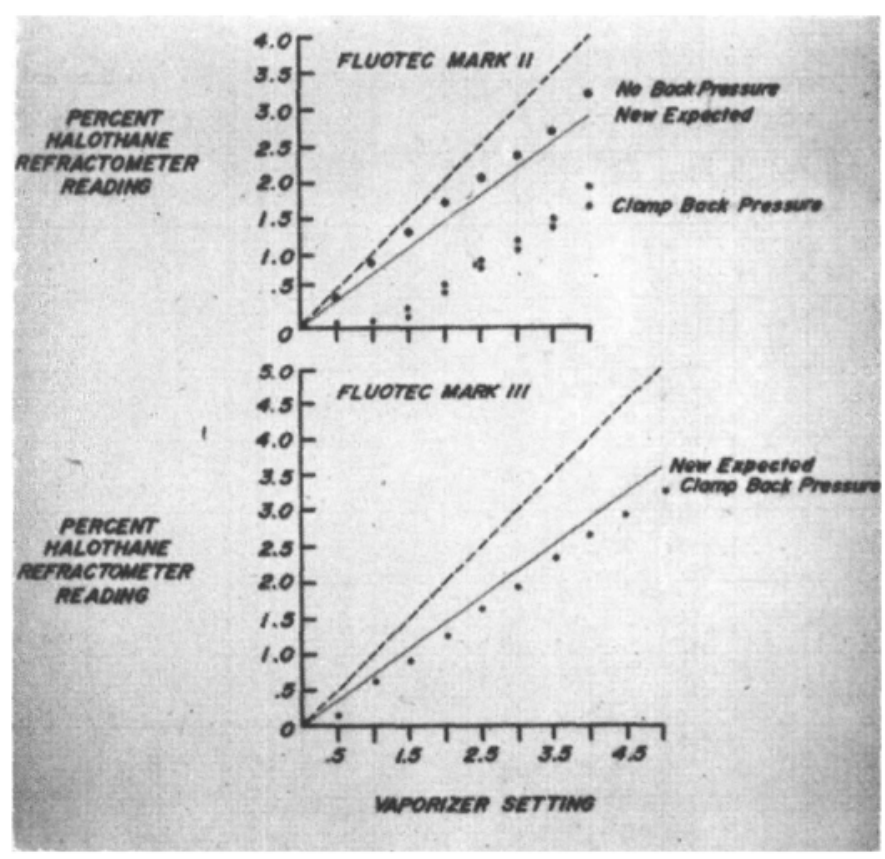

Figune 10. Upper graph shows results when back pressure into the Fluotec Mark II is created by clamping the effluent tube. Lower graph shows results with the Fluotec Mark III. 
markedly reduces delivered concentrations. Similar results are obtained with the other vaporizers. This pressure effect can be nicely accounted for by physical principles. Thus, at $20^{\circ} \mathrm{C}$ within a vaporizer, halothane exerts a saturated vapour pressure of $243 \mathrm{~mm} \mathrm{Hg}$. The pressure of saturated vapour only varies with temperature, and at a vaporizer setting of 1 per cent should mean $1 \mathrm{cc}$ of halothane vapour per $100 \mathrm{cc}$ of gas. If the pressure within the vaporizer were increased to $760+250=1010 \mathrm{~mm} \mathrm{Hg}$ by an obstruction downstream, the saturated pressure of halothane would still be $243 \mathrm{~mm} \mathrm{Hg}$; but now the total pressure exerted would be $1010 \mathrm{~mm} \mathrm{Hg}$, so that the concentration of halothane delivered will be reduced by a fraction of $760 / 1010$ or $3 / 4$. If we now move distal to the obstruction (Venturi circulator or clamp), the pressure returns to $760 \mathrm{~mm} \mathrm{Hg}$, and, according to Boyle's Law, both gases will expand and the concentration of halothane remain the same. Therefore the new halothane vapour concentration will be represented by $760 / 1010 \times 1$ per cent $=.75$ per cent - this at a 1 per cent setting.

We can now calculate a new expected concentration for each setting on the vaporizer, knowing the back pressure of the Venturi circulator. This has been done, and the line marked in Figure 10 indicates this new expected concentration delivered. Figure 9 indicates that the vaporizers studied here do not deviate from this physical principle.

Figure 9 also demonstrates that at 0 setting the Fluotec Mark II was also delivering halothane. This can be accounted for by the pushing forward of the spindle

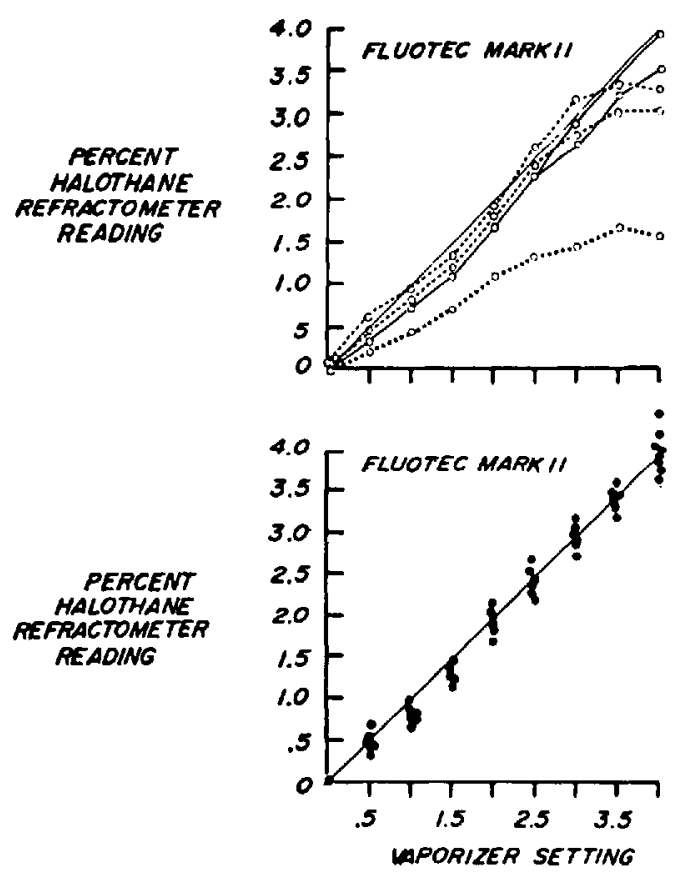

Figure 11. Lower graph shows accurate Fluotec Mark I vaporizer remaining accurate after local servicing. Upper graph shows marked improvement after servicing Fluotec Mark $\boldsymbol{~}$. 
by the back pressure within the vaporizer. This effect was not seen with any other type of vaporizer.

With regard to cleaning, two Fluotecs were chosen: $(a)$ one which was quite accurate, to see if local servicing would worsen its accuracy - in Figure 11, lower graph, it did not; and $(b)$ another vaporizer, upper graph, which was quite inaccurate, as indicated by the dots. As can be seen in Figure 11, upper graph, there was a marked improvement on cleaning by our technicians (dashes). It must be appreciated, however, that mechanical faults such as bent spindles, notches in the spiral groove, or corrosion of the bimetallic strip could not be expected to improve with this cleansing technique. There was a further slight improvement with recalibration by the manufacturer (solid lines), but again this correction might have been major had the fault been mechanical. Both sets of results, ours and the manufacturer's, compare well and indicate the comparable accuracy of the measurement techniques.

\section{Conclusions}

The inaccuracy of several of the Mark II vaporizers indicates the need for periodic maintenance. Cleansing of the spindle and soaking with ether were effective in restoring one vaporizer to accuracy and had no effect on another already accurate one. Recalibration by the manufacturer resulted in minimal improvement in accuracy after our cleansing. It is suggested that cleansing could be used as a temporary measure but that periodic recalibration as recommended by the manufacturer should be carried out.

The Drager-Vapor and Copper Kettle vaporizers apparently need little maintenance. Two new Mark Ins, the Mark II Fluotecs, and one Copper Kettle vaporizer were the only ones which delivered no halothane when shut off, although all vaporizers studied had a specific mechanism to prevent halothane from leaking into the bypass gas. In the face of back pressure the Fluotec Mark is delivered halothane at a 0 setting. If there is a hepatitic reaction to halothane, and if this is a hypersensitivity phenomenon, then many patients coming to the operating theatre may be sensitized inadvertently.

The new Venturi circulator creates a very high back pressure and results in a lower concentration delivered by each of the vaporizers studied in accordance with the physical principles outlined.

\section{RÉSUMÉ}

A la suite de certains doutes sur la précision des vaporisateurs en anesthésie clinique, nous avons entrepris une étude de plusieurs types de vaporisateurs d'halothane en usage clinique afin d'établir jusquà quel point ils étaient fables. Nous avons également inclus le circulateur Neff Venturi pour déterminer son effet sur la précision.

Le manque de précision d'un grand nombre de vaporisateurs Mark I implique le besoin d'un entretien périodique. Le nettoyage de la clef et un bain dans l'ether ont été suffisants pour rétablir la précision. A la suite de notre nettoyage, une 
récalibration par le manufacturier n’a apporté qu'une faible amélioration dans la précision. Comme mesure temporaire, on suggère de recourir au nettoyage mais, comme le recommande le manufacturier, une récalibration périodique s'impose.

Selon toute apparence, le Drager et le "Copper Kettle" requièrent peu d'entretien. Deux nouveaux vaporisateurs Mark III, un Mark II Fluotec et un "Copper Kettle" sont les seuls qui, une fois fermés, ne laissaient pas passer d'Halothane, bien que tous les vaporisateurs étudiés possédaient un mécanisme spécifique pour prévenir les fuites d'halothane dans le débit gazeux. Si l'on faisait une pression rétrograde, le fluotec Mark II vaporisait de l'halothane en position zéro. S'il survient une réaction hépatique à l'halothane et que cette réaction est un phénomène d'hypersensibilité, il peut arriver, à notre insu, que plusieurs malades passant aux salles d'opération soient sensibilisés.

Le nouveau circulateur Venturi engendre une très haute pression rétrograde et il s'ensuit que les vaporisateurs étudiés débitent une concentration plus basse d'après les principes physiques énoncés.

\section{ACKNOWLEDGMENTS}

The author wishes to thank Professor L. E. Morris and the anaesthetic staff at St. Michael's Hospital in Toronto for their stimulation and criticism of the experiments and the paper. The Mark in Fluotec vaporizers and the Rayleigh Interference Refractometer were supplied courtesy of Fraser Sweatman (Canada) Limited. Halothane was supplied by Ayerst.

\section{REFERENCES}

1. MacKay, J. M. Clinical Evaluation of Fluothane with Special Reference to a Controlled Percentage Vaporizer. Canad. Anaesth. Soc. J. 4: 235 (1957).

2. HILL, D. W. Halothane Concentrations Obtained with a Fluotec Vaporizer. Brit. J. Anaesth. 30: 563 ( 1958 ).

3. HrL, D. W. Halothane Concentrations Obtained with a Drager "Vapor" Vaporizer. Brit. J. Anaes. 35: 285 (1963).

4. Adner, M. \& Hallen, B. Reliability of Halothane Vaporizers. Acta anaesth. scandinav. 9: 233 (1965).

5. Goldh, T.; Hallen, B.; OkMIAN, L.; Wariln, A; \& Stern, B. The Concentration of Halothane by the Combined Use of Fluotec Vaporizer and Engstrom Respirator. Acta anaesth. scandinav. 8: 97 (1964).

6. HII., D. W. \& Lowe, H. J. Comparison of Concentration of Halothane in Closed and Semiclosed Circuits during Controlled Ventilation. Anesthesiology. 23: 291 (1962).

7. Cole, J. R. The Use of Ventilators and Vaporizer Performance. Brit. J. Anaesth. 38: 646 (1966).

8. Andreesen, I. H. \& BaY, J. Halothane Concentrations Obtained by the Combined Use of the Manley Ventilator and the Fluotec Vaporizer. Brit. J. Anaesth. 38: 641 (1966).

9. Neff, William B.; Srmpson, F. B.; \& Thompson, R. A Venturi Circulator for Anesthetic Systems. Anesthesiology. 29: 838 (1968).

10. Morris, L. E. A New Vaporizer for Liquid Anesthetic Agents. Anesthesiology. 13: 587 (1952).

11. Edmonson, W. Gas Analysis by Refractive Index Measurement. Brit. J. Anaesth. 29: 570 (1957).

12. Trtel, J. H.; Lowe, H. J.; Elam, J. O.; Grosholz, B. S. Quantitative Closed-Circuit Halothane Anaesthesia. Anaesth. \& Anal. 47:560 (1968).

13. Eger, E. I., I; Larson, C. P., Jr.; \& Severinghaus, J. W. The Solubility of Halothane in Rubber, Soda Lime, and Various Plastics. Anesthesiology 23: 356 (1962). 